\title{
Rapid identification of three waterborne pathogens in water samples by multiplex touchdown PCR
}

\author{
Hou Yanjiao 1, 2, a , Li Guanlin 3, b, Shao Chen ${ }^{1, c}$, Shao Shihe ${ }^{1, d *}$ \\ ${ }^{1}$ School of Medicine, Jiangsu University, No. 301 Xuefu Road, Zhenjiang 212013, \\ Jiangsu Province, China \\ ${ }^{2}$ Dezhou People's Hospital, No.1751 New Lake Street, Dezhou 253014, Shandong \\ Province, China
}

${ }^{3}$ Department of Environmental Science and Ecological Engineering, Korea University,

Seoul 136-713, Korea

aemail: houyanjiao@126.com, bemail:Guanlin.li1207@gmail.com,

cemail: 54236100@qq.com, demail: shaoshihe2006@163.com

Key words Vibrio parahemolyticus, Yersinia enterocolitica, Shigella, multiplex touchdown PCR

\begin{abstract}
The purpose of this study was to develop a multiplex touchdown PCR to identify three waterborne pathogens in water samples. Specific primers based on VP1332, inv and ipaH gene sequences were designed for $V$. parahaemolyticus, $Y$. enterocolitca and Shigella, respectively. By optimizing reaction conditions, assays obtained high specifity, sensitivity and repeatability. The detection limit can be as low as $0.005 \mathrm{ng} / \mu \mathrm{V}$. parahaemolyticus and $0.5 \mathrm{ng} / \mu \mathrm{l}$. enterocolitca and $0.005 \mathrm{ng} / \mu \mathrm{l}$ of Shigella respectively. The detection process was about 3 4 hours, saving a lot of time compared with microbiological culture method that required $2 \sim 3$ days. The system could be useful for the detection of multiple pathogens in water samples to protect public health.
\end{abstract}

\section{Introduction}

Waterborne pathogens have posed a considerable threat to public health worldwide. From May to June 2012, a waterborne illness outbreaking in drinking water in Seoul induced watery diarrhea and vomiting of the local residents[1]. In March 2012, more than 3600 people developed gastroenteritis symptoms in a district with 37264 inhabitants in central Greece[2]. The United States is one of the safest countries in the drinking water, they take a series of measures to clean it, but the disease outbreaks caused by drinking water still occurred.

Among the waterborne pathogens currently indwelled in water samples, $V$. parahaemolyticus, $Y$. enterocolitca and Shigella are frequently reported as the causative agents. V. parahaemolyticus was a significant cause of human gastrointestinal disorders worldwide, Y. enterocolitca and Shigella could cause inflammatory diarrhea and sepsis[3,4].

A real time PCR assay for the detection of $V$. parahaemolyticus in seafood samples was 
developed. Quantitative PCR (qPCR) methods were used to detect Y. enterocolitica in surface water, and drinking untreated water[5]. Duplex PCR assay for the detection of pathogenic $Y$. enterocolitca strains has been developed. Shigella DNA was detected by real-time PCR in Nha Trang. Real-time quantitative PCR have successfully been performed to identify pathogens. However, they are very expensive for routine use in common testing laboratories.

In this study, a multiplex touchdown PCR with high specificity, sensitivity and repeatability was developed to identify $V$. parahaemolyticus, $Y$. enterocolitca and Shigella simultaneously in water samples. The expected sizes of PCR amplifications were 870bp, 393bp and 193bp, respectively. The detection limit can be as low as $0.005 \mathrm{ng} / \mu \mathrm{l}$. parahaemolyticus and $0.5 \mathrm{ng} / \mu \mathrm{l} Y$. enterocolitca and $0.005 \mathrm{ng} / \mu \mathrm{l}$ of Shigella respectively. the approach could provide a powerful supplement to conventional methods for more quick detection and monitoring of waterborne pathogens infection.

\section{Materials and Methods}

Strains and growth media Strains used in this study were listed in Table 1. Y. enterocolitca was kindly provided by Dr. Shi Lining; other reference strains were collected and preserved in our laboratory[6] . V. parahaemolyticus was cultured on Thiosulfate citrate bile salts sucrose agar culture medium(TCBS) (Hopebio, China) in $37^{\circ} \mathrm{C}$ for $18 \sim 24 \mathrm{~h}, Y$. enterocolitca was prepared in Luria-Bertani medium (LB) (Oxoid, UK) in $28^{\circ} \mathrm{C}$ for $18 \sim 24 \mathrm{~h}$, Shigella and Salmonella paratyphi A were propagated and maintained on Salmonella-Shigella medium (SS) (Hang Wei, China) in $37^{\circ} \mathrm{C}$ for 18 24h , other strains were cultured on Chocolate agar and Blood agar Blood agar in $37^{\circ} \mathrm{C}$ for $18 \sim 24 \mathrm{~h}$.

Table1. Related strains for evaluation of specificity of PCR primers

\begin{tabular}{lccc}
\hline \multicolumn{1}{c}{ Organism } & VP1332 & inv & ipaH \\
\hline Acinetobacter baumannii ATCC®19606TM & - & - & - \\
Moraxella (Branhamella) catarrhalis ATCC® 25238TM & - & - & - \\
H. influenza ATCC® 10211TM & - & - & - \\
S. pneumoniae ATCC® 49619TM & - & - & - \\
Staphylococcus aureus ATCC® 25923TM & - & - & - \\
Escherichia coli ATCC® 25922TM & - & - & - \\
Pseudomonas aeruginosa ATCC® 27853TM & - & - & - \\
Klebsiella pneumoniae ATCC® 700603TM & - & - & - \\
Enterococcus faecalis ATCC® 29212TM & - & - & - \\
M. bovis & - & - & - \\
M. tuberculosis & - & - & - \\
M. smegmatis & - & - & - \\
M. bovis BCG & - & - & - \\
Salmonella paratyphi A & - & - & - \\
V. parahaemolyticus & - & - & - \\
Y. enterocolitca & - & - \\
Shigella & - & - \\
\hline
\end{tabular}

Oligonucleotide primers Basing on these sequences designed specific primers using Primer Premier 6.0,the primers sequences are listed in Table 2. The specificity of the designed primers was 
tested using Primer-BLAST (http://www.ncbi.nlm.nih.gov/tools/primer-blast/).

Table 2. Primer sequences and product sizes used in this study

\begin{tabular}{|c|c|c|c|c|c|}
\hline Bacteria & $\begin{array}{l}\text { Target } \\
\text { gene }\end{array}$ & $\begin{array}{l}\text { DNA } \\
\text { sequences }\end{array}$ & Primers & Sequence (5'-3') & $\begin{array}{l}\text { Product } \\
\text { sizes (bp) }\end{array}$ \\
\hline$V$. & VP1332 & NC_004603 & VP1332-F & TACGCTGAAGATAAACTAACGG & 870 \\
\hline parahaemolyticus & & & VP1332-R & TGCGGAAGAAGACTTACGAG & \\
\hline \multirow[t]{2}{*}{$Y$. enterocolitica } & inv & X53368 & $I n v-\mathrm{F}$ & ACCACGGCAATAGTTCTAATC & 393 \\
\hline & & & $\operatorname{Inv}-\mathrm{R}$ & CGGCAACAATATCAGATGGAGA & \\
\hline \multirow[t]{2}{*}{ Shigella } & ipaH & NC_004741 & ipaH-F & CGCCATATCAGAGTCATCACT & 193 \\
\hline & & & $i p a H-\mathrm{R}$ & TGCGTGCAGAGACGGTAT & \\
\hline
\end{tabular}

Genomic DNA extraction Genomic DNA from pure cultures was extracted using minibest bacterial genomic DNA extraction (TRANS, CHINA); for water samples, the bacteria of $100 \mathrm{~mL}$ water samples were firstly concentrated by membrane filtration, then extracting genomic DNA from the membrane with boiling methods. As follows, we put the membrane filtration into a $1.5 \mathrm{ml}$ eppendorf tube, and added 500ul sterile distilled water into eppendorf tube, making the membrane fully immersed in water. Then the eppendorf tube was boiled for 15 minutes to release the bacterial DNA, through centrifugation at $12000 \mathrm{rpm}$ for 10 minutes collected the bacterial DNA and, stored at $-20^{\circ} \mathrm{C}$ until required for further study.

\section{Results}

Optimization of multiplex touchdown PCR system After systematic optimization of amplification parameters, the best results were obtained with $25 \mu \mathrm{l}$ volume of PCR mixture containing $1 \mathrm{X}$ PCR buffer, $2.5 \mathrm{mM} \mathrm{MgCl} 2,0.3 \mathrm{mM}$ dNTP, $1.5 \mathrm{U}$ Taq DNA polymerase, $0.2 \mu \mathrm{M}$ of VP1332 primer set, $0.2 \mu \mathrm{M}$ of ipaH primer set, $1.2 \mu \mathrm{M}$ of inv primer set, $0.1 \mu \mathrm{g} / \mu \mathrm{l} \mathrm{BSA}, 2 \mu \mathrm{l}$ DNA template and sterile distilled water. The system was performed using the touchdown PCR conditions: an initial denaturation at $94^{\circ} \mathrm{C}$ for $5 \mathrm{~min}$, followed by 20 cycles of $94^{\circ} \mathrm{C}$ for $30 \mathrm{~s}, 61^{\circ} \mathrm{C}$ $\left(0.5^{\circ} \mathrm{C}\right.$ decrease per cycle) for $30 \mathrm{~s}, 72^{\circ} \mathrm{C}$ for $1 \mathrm{~min}$, then another 20 cycles of $94^{\circ} \mathrm{C}$ for $30 \mathrm{~s}, 51^{\circ} \mathrm{C}$ for $30 \mathrm{~s}, 72^{\circ} \mathrm{C}$ for $1 \mathrm{~min}$, and a final extension step at $72^{\circ} \mathrm{C}$ for $7 \mathrm{~min}$.

Specificity of the multiplex touchdown PCR assay To evaluate the specificity of primers used in the study, DNA template prepared from other 14 strains in addition to objective strains (shown in Table 1) were tested using the established multiplex touchdown PCR system. As shown in Fig. 1, the multiplex touchdown PCR produced specific bands of $V$. parahaemolyticus, $Y$. enterocolitica, Shigella. No cross amplification with other species was observed.

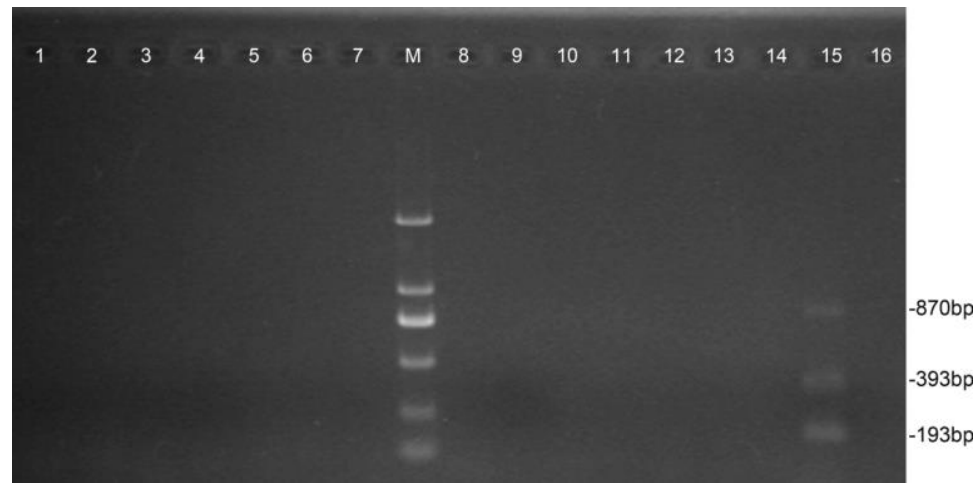

Fig.1. Specificity of the multiplex touchdown PCR assay performed on DNA from pure cultures. 
Lane M: DL2000 marker; Lanes 1-14: Staphylococcus aureus ATCC® 25923TM; Moraxella (Branhamella) catarrhalis ATCC® 25238TM; Streptococcus pneumoniae ATCC® 49619 TM; Klebsiella pneumoniae ATCC® 700603TM; Acinetobacter baumannii ATCC®19606TM; Enterococcus faecalis ATCC® 29212TM; H. influenza ATCC® 10211TM; M. smegmatis; M. bovis;Escherichia coli ATCC ${ }^{2}$ 25922TM; Pseudomonas aeruginosa ATCC $(27853 \mathrm{TM}$; . tuberculosis; M. bovis BCG; Salmonellaparatyphi A; Lane15: V. parahaemolyticus, Y. enterocolitca, Shigella; lane16: Sterile distilled water.

Sensitivity of the multiplex touchdown PCR assay Different concentrations of DNA templates were tested with multiplex touchdown PCR , and then the lowest DNA concentration that produced visible band was considered as the detection limit. The results displayed that the detection limit of DNA was as few as $0.005 \mathrm{ng} / \mu \mathrm{l} V$. parahaemolyticus and $0.5 \mathrm{ng} / \mu \mathrm{l} Y$. enterocolitca and $0.005 \mathrm{ng} / \mu \mathrm{l}$ of Shigella respectively (Fig. 2).

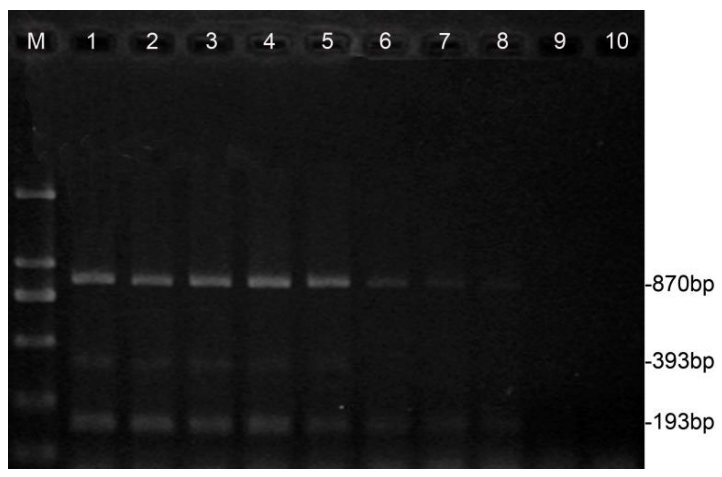

Fig. 2. Sensitivity of the multiplex touchdown PCR assay

Lane M:DL2000 marker; Lane 1-10 the serial dilutions of chromosomal DNA extracted from $V$. parahaemolyticus, $Y$. enterocolitca, Shigella strains, from left to right, 10, 5, 2.5, 1.5, 0.5, 0.15, $0.015,0.005,0.001,0.0005 \mathrm{ng} / \mu 1$.

Repeatability of the multiplex touchdown PCR assay Using the established multiplex touchdown PCR detected many times to the same sample, and obtained consistent results. It indicated that the assay had good repeatability.

Multiplex touchdown PCR applied to single and multiple pathogens infection In fact, Infection can be caused by single pathogen or multiple pathogens together. In order to verify the practicality of the detection, different random combinations of pathogens were added in drinking water, then genomic DNA of these pathogens were detected by optimized multiplex touchdown PCR. Different combinations of pathogens wouldn't interfere with the stability and accuracy of the system (Fig. 3). This method has a good practicality, and promotional value.

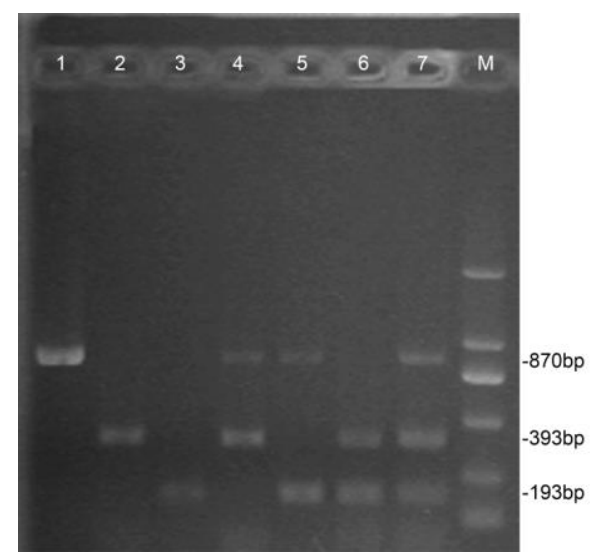

Fig. 3. Multiplex touchdown PCR applied to single and multiple pathogens infection. 
Lane M: DL2000 marker; Lane 1: V. parahaemolyticus; Lane 2: Y. enterocolitica; Lane3: Shigella ; Lane 4: V. parahaemolyticus and Y. enterocolitica ; Lane 5: V. parahaemolyticus and Shigella ; Lane 6: Y. enterocolitica and Shigella ; Lane 7: V. parahaemolyticus, Y. enterocolitica and Shigella.

Multiplex touchdown PCR detection applied to different types of water samples Genomic DNA from four types of water samples was extracted as the template of multiplex touchdown PCR assay; specific bands can be successfully amplified. The test results were consistent with traditional separation, but traditional identification needed $2 \sim 3$ days, multiplex touchdown time PCR detection required only $3 \sim 4 \mathrm{~h}$, so the detection time was greatly reduced. The results were as follows (Fig. 4).

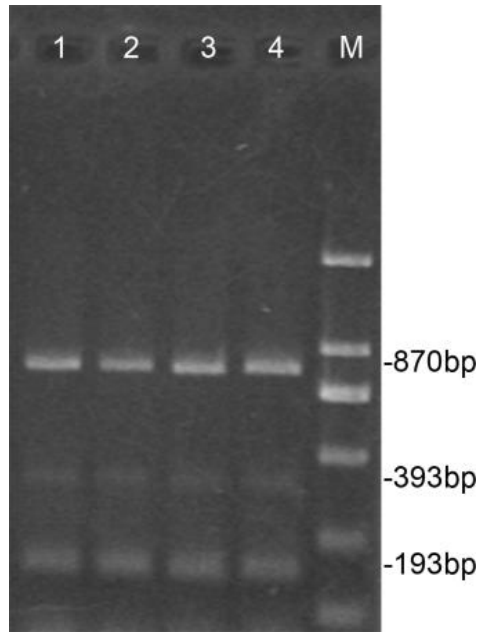

Fig. 4. Multiplex touchdown PCR detection applied to different types of water samples.

Lane M: DL2000 marker; Lane 1-4: lake water, tap water, distilled water, bottled purified water.

\section{Discussion}

The waterborne pathogens often caused many lethal human diseases and could be an important water safety issue in the worldwide. A rapid and accurate detection method is very important to identify and trace outbreaks of bacterial pathogens within the water supply.

Multiplex PCR could be applied to detect multiple target organisms in a single tube reaction to save time and labor[7], Touchdown PCR approach exploits the exponential nature of PCR, the appearance of additional mismatched products reduced or effectively abrogate. Multiplex touchdown PCR can save a great deal of time, and had a lower risk of cross-contamination.

In this work, we used VP1332 as a target gene of V.parahaemolyticus. the virulence gene did not exist in other Vibrio species. The positive rate of inv tested in 160 isolates $Y$. enterocolitca was $100 \%$, hence, we Chose inv gene as the target. It has been considered that the ipaH gene was the main target for detection of Shigella. We Chose ipaH gene as the target.

Hossain et al. have reported that the detection limit of mixed primers for detection of $V$. parahaemolyticus strains was $200 \mathrm{pg}$ [8], the detection limit of $V$. parahaemolyticus in our system was found to be lower, which was $0.005 \mathrm{ng}$, namely $5 \mathrm{pg}$. Although Chen et al. have stated the detection limit of Shigella to be $73.35 \mathrm{fg}[9]$, we were unable to obtain as low as their values $(0.005 \mathrm{ng})$. We have ever used the ail of Y. enterocolitca as the target, and its detection limit (5fg) was much lower than that of inv( $0.5 \mathrm{ng})$ in this study, but positive rate of virulence genes of ail gene was $94 \%$, not $100 \%$ (inv), some $Y$. enterocolitca strains lacked the ail gene. The possibility of false-negative results may occur, so we still chose the inv as the target. Although the infectious dose 
varies from pathogen types, the detection sensitivity of the multiplex assay in this study is within the infectious dose of most pathogens.

The test results were consistent with traditional separation. But the detection time is greatly reduced. The established system was proved to have specificity, sensitivity, good repeatability and high reliability. This method had a good practicality, and promotional value.

Although this method is rapid and time-saving, it is a fact that present PCR approaches cannot completely substitute all the advantages of conventional microbiological diagnostics. In addition, a broad spectrum of possible other bacterial pathogens could be missed when only multiplex touchdown PCR is conducted.

\section{Conclusion}

This method suggests a simple, fast, inexpensive, and reliable system for the practical detection of three pathogens in water samples. Further studies on the detection of other important pathogens and other samples will be developed.

\section{Acknowledgements}

This study was supported by grants from the provincial science and technology innovation and technology transfer of Jiangsu Province, China (BL2012047).

\section{References}

[1] E. J. Cho, J. Y. Yang, E. S. Leeet al. A waterborne outbreak and detection of cryptosporidium oocysts in drinking water of an older high-rise apartment complex in seoul[J]. Korean J Parasitol, 2013, 51(4): 461-466

[2] B. Liu, X. He, W. Chenet al. Development of a real time PCR assay for rapid detection of Vibrio parahaemolyticus from seafood[J]. Protein Cell, 2012, 3 (3): 204-212

[3] L. D. Goodridge. Bacteriophages for managing Shigella in various clinical and non-clinical settings[J]. Bacteriophage, 2013, 3(1): e25098

[4] D. Ottaviani, F. Leoni, E. Rocchegianiet al. An extensive investigation into the prevalence and the genetic and serological diversity of toxigenic Vibrio parahaemolyticus in Italian marine coastal waters[J]. Environ Microbiol, 2013, 15(5): 1377-1386

[5] B. M. Cheyne, M. I. Van Dyke, W. B. Andersonet al. The detection of Yersinia enterocolitica in surface water by quantitative PCR amplification of the ail and yadA genes[J]. J Water Health, 2010, 8(3): 487-499

[6] Y. C. Luo, Du P, J. Z. Zhaoet al. A multiplex touchdown PCR for detection of Streptococcus pneumoniae, Haemophilus influenzae type $\mathrm{b}$ and Mycobacterium tuberculosis complex in sputum samples[J]. Trop Biomed, 2012, 29(3): 422-428

[7] B. Wei, S. Y. Cha, M. Kanget al. Development and application of a multiplex PCR assay for rapid detection of 4 major bacterial pathogens in ducks[J]. Poult Sci, 2013, 92(5): 1164-1170

[8] M. T. Hossain, Y. O. Kim, I. S. Kong. Multiplex PCR for the detection and differentiation of Vibrio parahaemolyticus strains using the groEL, tdh and trh genes[J]. Mol Cell Probes, 2013, 27(5-6): 171-175

[9] J. Chen, J. Tang, J. Liuet al. Development and evaluation of a multiplex PCR for simultaneous detection of five foodborne pathogens[J]. J Appl Microbiol, 2012, 112(4): 823-830 